International Journal of Agriculture, Environment and Bioresearch

Vol. 06, No. 03; 2021

ISSN: $2456-8643$

\title{
SOCIO-ECONOMIC COMPONENT, COASTAL RESOURCE USE AND PERCEPTION, AND PARTICIPATION OF THE COASTAL COMMUNITIES/FISHING HOUSEHOLDS IN TAPEL, GONZAGA, CAGAYAN
}

\author{
Gerlie U. Bayani, Froilan A. Pacris Jr. and Marvin V. Baloloy \\ College of Agriculture, Cagayan State University-Gonzaga ,Flourishing, Gonzaga Campus, Cagayan3513, \\ Philippines
}

https://doi.org/10.35410/IJAEB.2021.5644

\begin{abstract}
The study generally identified and analyzedthe ecological status and socio-economic status of coastal communities of Barangay Tapel, Gonzaga, Cagayan, and also their dependency on the floral and faunal resources of water. The studycarried out interviews based on questionnaires and useddescriptive survey research design.

The results of the study revealed that most of the respondents have a low level of education with fishing as the main source of income. Fishing as a source of income tells that BarangayTapel is a coastal community. Fishing activities are alsodone to the estuary where mangrove trees thrive. Most of the respondents said that the benefits derived from the coastal environments are recreation/relaxation, bathing/swimming, andtransportand navigation. However, due to natural and anthropogenic disturbances, today, benefits derived from the coastal area are very limited since there are changes observed in coastal resources specifically on the fishing ground location andvolume of catch.

This generally implies that full understanding of socio-economic characteristics, coastal resource useand perception, and participation of the community plays animportant rolein the coastal resource restoration and management plans. Also, thisdatabase helps to understand the underlying causes of degradation and interventions needed in this community.
\end{abstract}

Keywords: Coastal Communities, Socio-economic, Perception, Mangroves, Fishery Resources.

\section{INTRODUCTION}

Mangrove forests are considered as a highly productive ecosystem which provides important ecological and economic good and services [1]. This includes as a natural barrier to reduce devastating impact of natural disasters such as typhoons, tsunamis, and storm surge. It also helps stabilize shorelines and provides breeding and nursing ground for marine and pelagic species. In addition to ecological benefits, mangrovesalso provide food, medicine, fuel and building materials for local communities.

In the Philippines, the current estimates of mangrove forests are less than half of what it once was and this remaining is in a degraded condition. These forests are least concerned and often 


\section{International Journal of Agriculture, Environment and Bioresearch}

Vol. 06, No. 03; 2021

ISSN: $2456-8643$

over utilized by the human communities [2] and the continued decline of the forest is caused by conversion to agriculture, aquaculture, tourism, urban development, and deforestation. Mangrove forests have been declining at a faster rate as compared to inland tropical forests and coral reefs.

In the province of Cagayan, it has amangrove area of 3,967.9 hectares which are distributed throughout the municipalities of Abulug, Aparri, Buguey, Calayan, Claveria, Gonzaga, Pamplona, SanchezMira, Santa Ana, and Santa Teresita [3]. Mangrove areas harbor at least 14 species of true mangroves and which is $35 \%$ of the country's mangrove species. In particular, in the municipality of Gonzaga, the status of the mangrove forests is poor with an average of $25 \%$ living mangrove forests. Most of the areas manifested severe cutting, heavy erosion and siltation specifically observed in Barangays Caroan and San Jose, where the largest tracts of mangrove forest in the municipality are located [3].

Obviously, the degradation of mangrove forest possesses negative consequences to disaster control and preparation, biodiversity, ecology, livelihood, and even the life condition of people in coastal communities. With this, restoration and conservation of mangrove forest in these coastal communities are essential. According to Lewis (2009), successful mangrove forest restoration requires careful analyses of number of factors in advance of attempting actual restoration [4]. A wide variety of restoration techniques have been developed, but the most critical point is to fit restoration efforts with the local physical and biological settings, selecting the right species and right locations [5]. The ecological aspects of mangrove restoration must alsocouple with considering the local community that has specific socio-economic conditions. A full understanding of the socio-economic status of the community can help the goal of restoration and can guide the management plans of the study. Interviews with local people may help to understand what are the underlying causes of degradation-even to researchers from exact sciences these socio-economic surveys are very important, as they are the only source of retrospective information.

The study identified and analyzed the ecological status and socio-economic status of coastal communities/fishing households of Barangay Tapel in Gonzaga, Cagayan, Philippines and also their dependency on the floral and faunal resources of water. This baseline information is a basic and prerequisite toolthat can be incorporated into a resource management context by recommending interventions that address the underlying factors behind coastal resource degradation.

\section{METHODS}

\subsection{Study Area}

The study was conducted in Barangay Tapel, Gonzaga, Cagayan, Philippines. Tapel is a barangay in the municipality of Gonzaga, in the province of Cagayan. Geographically, it is situated at approximately $18^{\circ} 17^{\prime} 39.4794^{\prime \prime}$ north latitude and $122^{\circ} 2^{\prime} 5.6394 "$ east longitude, in the island of Luzon[6]. The location of Barangay Tapel within the municipality of Gonzaga is shown in Figure 1. This was selected as the study area because of the presence of large tracts of mangroves within the area. 


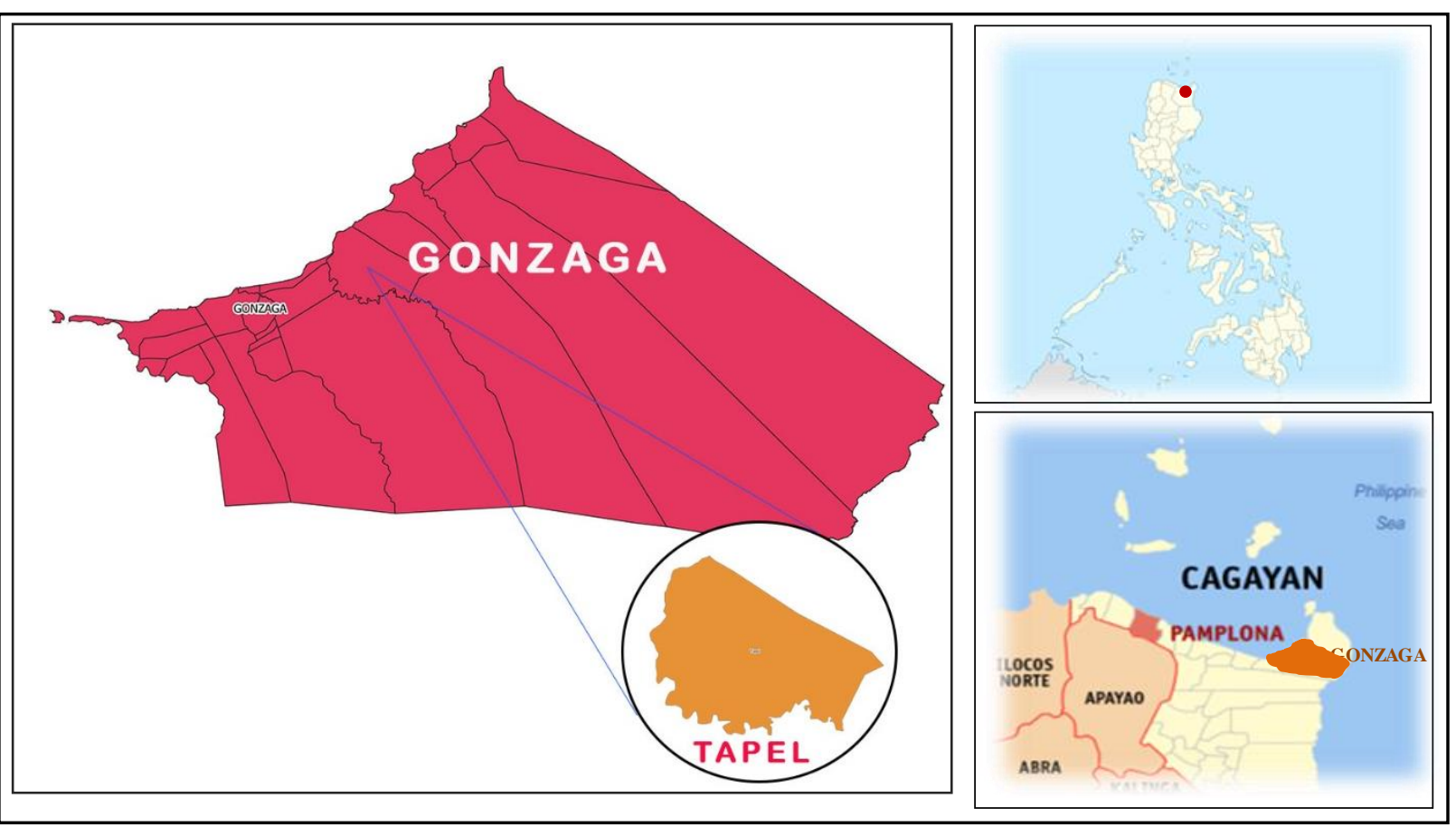

Figure 1. Location map of Barangay Tapel in Gonzaga, Cagayan, Philippines.

\subsection{Data collection}

Thirty-four individuals in the coastal community of Barangay Tapel were interviewed to elicit information on socio-economic status, coastal resource uses and status, and other issues relating to coastal resource management. The study determined the socio-economic information such as age, marital status, educational status, source of income, economic income, housing, household and productive assets, and fishing gears owned. Further, the study determined how respondents use the coastal resources. Respondents also asked regarding their observations on fishery resources and other coastal resources, particularly on the status of fishing ground location, the volume of fish catch per trip, the composition of the catch, size of fish, mangrove area, seagrass bed and seaweed area, coral reef area, and beaches five years ago and today.

\subsection{Research Design and Analysis}

The study conducted interviews (Figure 2) based on questionnaires to obtain information on the socio-economic component, coastal resource use, and participation of coastal communities/fishing households of Barangay Tapel in Gonzaga, Cagayan.

Descriptive statistics,including the use of frequency analysis, were used as a research design in the analysis of the datagathered.The datacollectedwere analyzed in terms of frequency, number or percentage and used asthe basis for ranking the responses. Half of the fishing households were served as sample sizes 


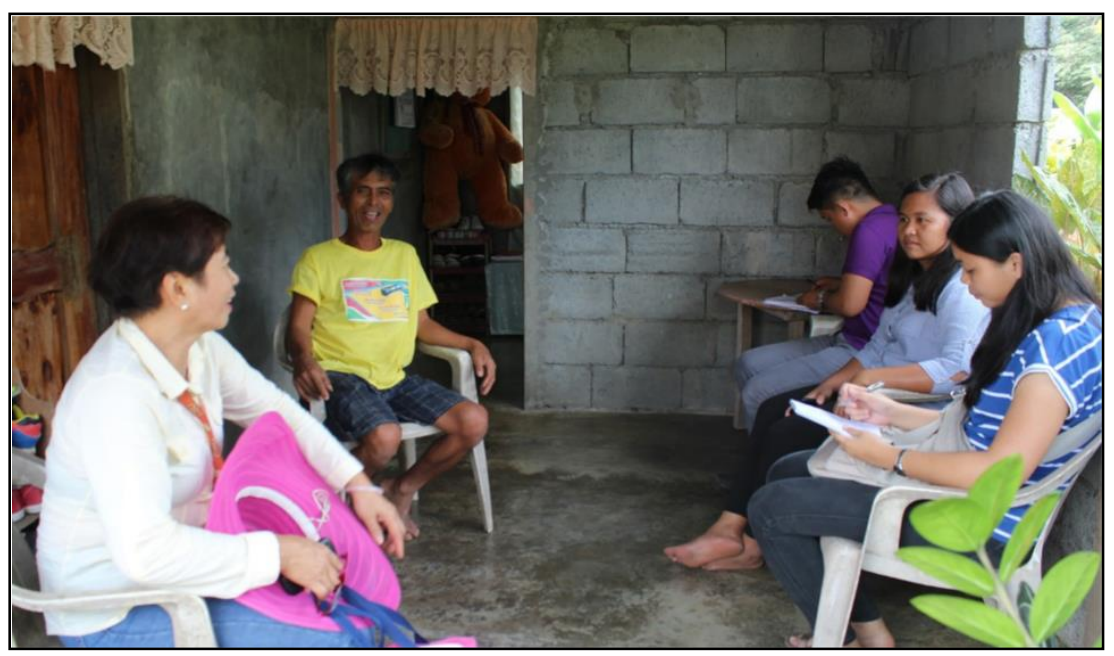

Figure 2. Conduct interviews with the local community

\section{RESULTS AND DISCUSSION}

Thirty-four individuals from the coastal community of Barangay Tapel were interviewed and the majority of them belong to the Tapel Fisherfolk Organization. This organization is headed by Mr. Manolo M. Paneda.

\subsection{Social Profileof the Coastal Community of Barangay Tapel}

\subsubsection{Age and Marital Status}

The respondents are grouped by age and the data show that the majority of respondents belong to age groups of 30 years to 69 years. Most of the respondents were locals in the area being surveyed. Respondents at these ages and also years of stay in the area have enough knowledge to respond to the questions implying reliability of the data collected. In terms of marital status, the majority of respondents $(94.44 \%)$ are married and the remaining $5.88 \%$ are single. On the other hand, respondents are not represented in other marital states such as common-law marriage (livein), single parent, separated person, and widow or widower.

\subsubsection{Educational Status}

With respect tothe highest educational attainment, $41.18 \%$ of the respondentshaveelementary graduate-level of education, followed by $23.53 \%$ graduate high school level and $17.65 \%$ did not graduate elementary level.Meanwhile, $11 \%$ and $5.88 \%$ of the respondents did not graduate college level and high school level, respectively. This data imply that respondents generally have 
a low level of education which is elementary level.

\subsection{Economic Profile of the Coastal Community in Barangay Tapel \\ 3.2.1. Source of Income and Economic Income}

Source of income and monthly income are very important aspects of the economic profile of respondents. Based from the Philippine Standard Occupational Classification by PSA (2012), all respondents are classified as skilled agricultural, forestry, and fishery workers. The figure shows the specific tasks performed by the respondents in Barangay Tapel. According to PSA (2012), skilled agricultural, forestry and fishery workers grow and harvest field or tree and shrub crops, gather wild fruits and plants, breed, tend or hunt animals, produce a variety of animal husbandry products, cultivate, conserve and exploit forests, breed or catch fish and cultivate or gather other forms of aquatic life in order to provide food, shelter, and income for themselves and their households. Itis observed in Figure that fishing is themain occupation or the main source of incomeof $50.70 \%$ of respondents. It can be noted that respondents are generally fisherfolks in which fishing is their major occupation. According to FAO (2016), these respondents are considered full-time fishers since they receive at least $90 \%$ of their livelihoods from fishing or spend at least $90 \%$ of their working time in that occupation [7]. As to age, fishing activity is carried out by $23.53 \%$ respondents in the $38-45$ age group. This tells that fishing is the main source of income of the community in Barangay Tapel. Additionally, the dominance of fishing implies that the barangay is a coastal community. Aside from fishing asa livelihood of respondents, there were $19.4 \%$ respondents who engaged in livestock production, $13.4 \%$ in farming, $10.4 \%$ in fish processing, $3.0 \%$ in fish trading and in boat construction.

For economic income, the majority of respondents (67.65\%)engaged in fishinghave a monthly income ranging from $\mathrm{P} 1,200$ to $\mathrm{P} 4,499$. The income of most respondents is below the poverty thresholds of Php 10, 481.00 for the year 2019 (PSA, 2020). This implies that fishers were making just enough money to meet household living expenses.

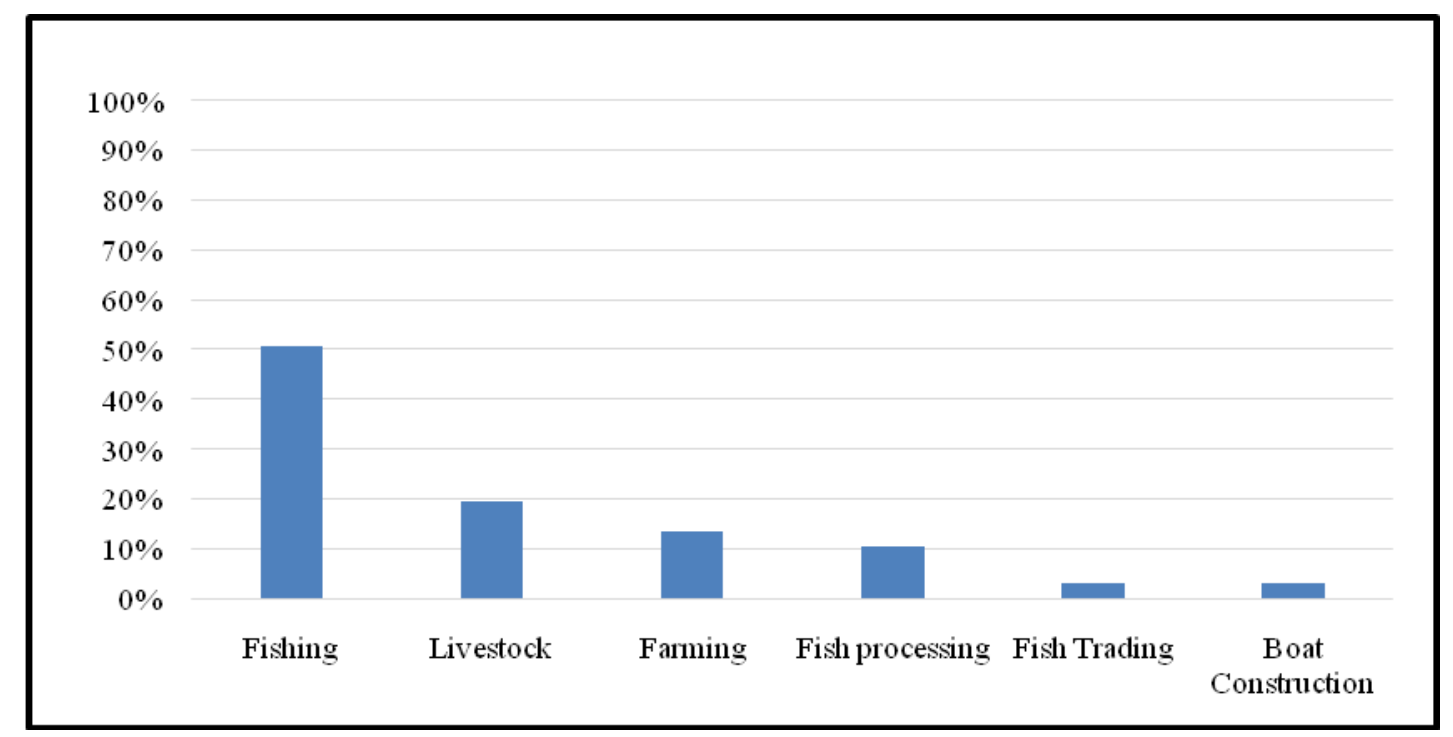

Figure 3.Occupations of the respondents in Barangay Tapel 


\subsubsection{Housing, Household and Productive Assets}

The profile of the respondents in terms of housing, household, and productive assets was determined by identifying their type of building/house, construction materials of the roof and construction materials of the outer wall, land ownership status, tools/equipment owned in farming, household items owned, water source. In terms of building or house-type, all respondents live in a single-typed house, the majority of the respondents have mixed but predominantly light materials of construction materials of the house's roof, and the majority of the respondents have mixed but predominantly permanent materials of the house's outer wall. But, among respondents, the majority of them rented their residence. Meanwhile, the common household items of the respondents are wood stove, TV, gas stove, antenna/satellite disc, boat, engine (for boat), DVD player, refrigerator, radio and vehicle/motorcycle.

\subsubsection{Fishing gears owned}

In terms of fishing gears used in fishing activities, it is shown in Figure 3 that themajority of the respondents $(60 \%)$ used hook and line as fishing gears in capturing fish, followed bygill net (26\%), scoop net"pangsalok"(7\%), filter net (5\%), and baby trawl (2\%). The hook and line method is the most productive fishing gear in municipal water (http://map.seafdec.org). Meanwhile, it was observed that some respondents used baby trawl and filter net. According to Fisheries Administrative Order (FAO) 201 by BFAR, it prohibits the operation of municipal and commercial fishing boats using active gears in municipal waters, bays, and fishery management areas. Some of the respondents violated the rules and regulation of FAO 201 since they used active gears such as beach seine, danish seine, baby trawl, and filter net in capturing fish in marine waters. The main potential negative impact of these fishing gears on living resources is when too many small-sized organisms and non-target species are caught and sometimes discarded. This finding shows that the use of active fishing gears is prohibited, but the local community of Tapel still used these gears in capturing fish and other fishery resources. Twin fish is mainly caught using hook and line and gillnet, while climbing perch "araro" in scoopnet method, crabs "alimasag" in filter net,and spanish mackerel "tanguigui" in baby trawl method.

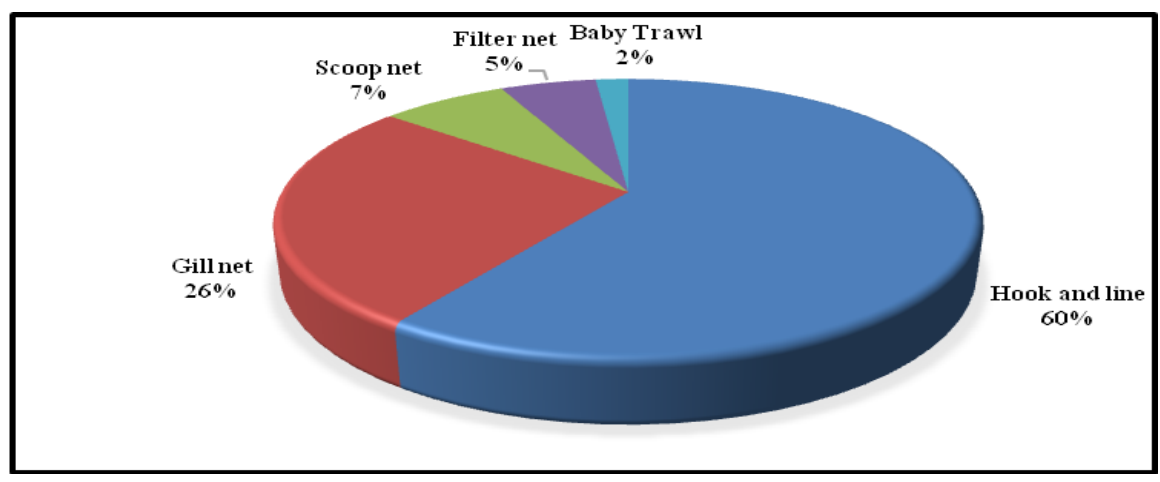

Figure 3. Fishing gears used by the respondents 


\section{International Journal of Agriculture, Environment and Bioresearch}

Vol. 06, No. 03; 2021

ISSN: $2456-8643$

\subsection{Coastal resource use, perception and participation of coastal community}

\subsubsection{Mangrove-based activities}

Fishing activities are not only limited to marine waters, but also to theestuary where mangrove trees thrive. Among the 34 respondents, 14 of them engaged in fishing in mangrove watersusing the hook and line method.This means that mangrove resources also provide asource of food and livelihood to the community since these resources are valuable habitats for fish, shellfish, and crustaceans specifically crabs and shrimps. The same finding was observed in the study of Eaton et al. (2009), in which mangrove is also used as a source of fish, shrimps, and crabs by some members of the community [8]. Meanwhile, according to the respondents, mangrove cutting and typhoon are two main factors thatmay affect mangrove forestareas.

Culture of mudcrab and fish in mangrove areas could be also the source of livelihood of the community near the area, considering the biological, physical, and chemical characteristics of mangrove waters in Barangay Tapel observed in the study of Pacriset al. (2020) [9].

\subsubsection{Problems and conflicts affectingcoastal resources}

In terms of fisheries management issues, all respondents are not aware ofgeneric issues such as depleted fishery resources, degraded fishery habitats, intensified resource use competition and conflict, unrealized potential of aquaculture and commercial fisheries and also on institutional issues such as limited institutional capabilities, inadequate/inconsistent fisheries policies, and weak institutional partnerships. This indicates that they lack knowledge about fishing management and institutional issues thatcan be the one reason in having conflicts in fishing livelihood. Martinuzziet al. (2009) states that management plans have been seen to be beneficial to specific areas [10]. Government regulations require specific management plans but it would be difficult for the local communities of Barangay Tapel to assemble the necessary documentation and set up the appropriate plan since they lack knowledge of fisheries management. Respondents said that mining and weather condition are the main factors that affect their fishing livelihood. Meanwhile, 34 respondents have attended training or seminar and all of them are willing to attend training or seminar on organic agriculture, aquaculture, livestock production, and vegetable production.

Excessive use of coastal resources, lack of knowledge and awareness on fisheries management, illegal human activities and natural disaster are the factors thatcould affect the coastal resources and eventually the fishing livelihood of the community. This finding supports the statement ofCinner (2000) that the use of coastal resources is dependent upon socioeconomic variables [11].

\subsubsection{Observations on the status of fishery resources and other coastal resources}

Most of the respondents said that the benefits derived from coastal environments are recreation or relaxation, bathing or swimming, and transport and navigation. Nowadays, benefits derived from coastal areas are noticeably limiting due to both human and natural causes. Referring to Table1, there were changes observed in coastal resourcesover the last five years and nowadaysspecifically on the fishing ground locationand theaverage volume of catch per trip.Five years ago, the fishing ground location was about $1 \mathrm{~km}$ to $8 \mathrm{~km}$, while today the fishing ground location is from $1 \mathrm{~km}$ to $17 \mathrm{~km}$. When comparing the volume of fish catch per trip between five 
years ago and today, a noticeably decrease was observed from $10 \mathrm{~kg}-76 \mathrm{~kg}$ to $5 \mathrm{~kg}$ to $20 \mathrm{~kg}$, respectively. This indicates that there are lower catches observed today than before. On the other hand, there were no observed differences in the composition of the catch, size of fish, mangrove area, seagrass bed and seaweed area, coral reef area, and beaches over the last five years and now.

Table 1. Observations on the status of fishery resources and other coastal resources

\begin{tabular}{|l|l|l|}
\hline Coastal Resources & Five years ago & Today \\
\hline Fishing ground location & From 1km-8km & From 1km-17km \\
\hline $\begin{array}{l}\text { Average volume of } \\
\text { catch per trip }\end{array}$ & From 10kg-76kg & From 5kg-20kg \\
\hline Composition of catch & $\begin{array}{l}\text { Snapper, baraniti, twin fish, } \\
\text { moon fish, bilis, trevally, } \\
\text { salmon, swordfish, dolphin fish, } \\
\text { dariway, spanish mackerel }\end{array}$ & $\begin{array}{l}\text { Snapper, baraniti, twin fish, } \\
\text { moon fish, bilis, trevally, } \\
\text { salmon, swordfish, dolphin fish, } \\
\text { dariway, spanish mackerel }\end{array}$ \\
\hline Size of fish & from 50g-8,050 g & from 5g-8,578 g \\
\hline Mangrove area & Dense & Dense \\
\hline $\begin{array}{l}\text { Seagrass bed and } \\
\text { seaweed area }\end{array}$ & Dense & Dense \\
\hline Coral reef area & Dense & Dense \\
\hline Beaches & Clean, beautiful, natural & Clean, beautiful, natural \\
\hline
\end{tabular}

In general, $58.82 \%$ of the respondents said that the food and income from fishing are not enough for their living. But, even if their income from fishing cannot sustain their daily lives $73.53 \%$ respondents are not willing to leave livelihood from fishing if there is an opportunity to get a job that is better than fishing. Also, most of the respondents (91.18\%)want their children to become professionals and have a better life. To achieve these aspirations, they want to seek support from the government such as free fishing gears, fishing boats and equipment, scholarship, livelihood program, land, and money.

\section{CONCLUSION}

The study found that the coastal resources in the coastal area of Barangay Tapel generate economic and environmental benefits. The economic status of the coastal community of the barangay reflected by the source of income, primarily fishing. This income indicates community needs mangroves and other coastal resources for their living aside from its ecological benefits. However, it was found out in the study that these resources have been extensively degraded because of resource-dependent communities, climate change, and human activities such as illegal use of fishing gears, mining, and deforestation. The study also concludes that there is no sustainable resource management since based on the results, it tells that most of the respondents have a low standard of education and lack of awareness on fisheries management and institutional issues. 


\section{International Journal of Agriculture, Environment and Bioresearch}

Vol. 06, No. 03; 2021

ISSN: $2456-8643$

This generally implies that full understanding of socio-economic characteristics, coastal resource use, and perception of the coastal community of Barangay Tapel, Gonzaga, Cagayan play important roles in the coastal resource restoration and management plans. Also, these help to understand the underlying causes of degradation and interventions needed in this community.

Based from the findings of the study, development of environment-friendly enterprise and livelihood opportunities for local communities are envisioned to address the prevailing poverty of resource-dependent communities and these will also motivate communities to protect natural resources specifically mangrove areas and fishery resources. Also, seminars and training are importantly needed for coastal communities to impart education to make them environmentally responsible and to make them realize the importance of coastal resources. This is seen as a mechanism to protect the forests while ensuring the well-being of the local communities that depend on them for survival and livelihood.

\section{REFERENCES}

[1] M. Zakaria, M. Rajpar,“Assessing the fauna diversity of Marudu Bay mangrove forest, Sabah, Malaysia, for future

Conservation,” Diversity, VII (2), pp. 137-148, 2015.

[2] M. Haritha, K.A.S.Nisha, P.R. Sekhar,"A study on mangrove ecology and socio-economic status of fishing

communities in coringa region of East Godavari district, Andhra Pradesh, India," International Journal of Fauna and

Biological Studies, IV (1),pp. 01-04, 2017.

[3] E.Q. Pasion,B.T. Tumaliuan, "State of the Mangroves in Cagayan," Mangrove Proceedings, pp. 55-58, 2015.

[4]R.R.Lewis,"Methods and criteria for successful mangrove forest restoration. Coastal Wetlands: An Integrated

Ecosystem Approach,” Elsevier,pp. 787-800, 2009.

[5]H.V.Lavieren, M. Spalding, D. Alongi, M.Kainuma, M.C.Godt, Z. Adeel,"Securing the Future of Mangroves, A Policy

Brief. United Nations University. Institute for Water, Environmental and Health, Hamilton, Canada, pp. 1-53. 2012.

[6] PhilAtlas, "Tapel, Municipality of Gonzaga, Province of Cagayan. [Online]. Available:

https://www.philatlas.com/luzon/r02/cagayan/gonzaga/tapel.html . [2021]

[7] U. Tietze, "Technical and socio-economic characteristics of small-scale coastal fishing communities, and opportunities for

poverty alleviation and empowerment," FAO Fisheries and Aquaculture Circular No. 1111. Rome, Italy, 2004.

[8] J.E.Eaton, H. Burton, M.D. Steer, E.M.S. Belle, “A Socio-economic study of mangrove perceptions and

Managementin the bay of Antsiranana: Ambalisakely, Abalibabe, Andohazompona, Ampasirikely and Antsisikala," Frontier

MadagascarEnvironmental Research Report Society for Environmental Exploration, UK and Institute of Marine Sciences, 
Vol. 06, No. 03; 2021

ISSN: $2456-8643$

Antsiranana,2009.

[9] F.A.Pacris, Jr., G.U. Bayani, M.V. Baloloy." Bio-physical and chemical assessment of Mangrove waters in Gonzaga,

Cagayan,International Journal of Biosciences.,XVI (6), pp. 241-248, 2020.

[10] S.Martinuzzi, W.A.Gould, A.E. Lugo, E. Medina, "Conversion and Recovery of Puerto Rican mangroves: 200

years of change," Forest Ecology and Management, CCLVII (1), pp.75-84, 2009.

[11] J.Cinner, "Socioeconomic influences on coastal resource use in Mahahual, Mexico (Master's thesis, University of

RhodeIsland), 2000. 